\title{
Algumas consideraçóes sobre o Campo DO BIOLÓGICO EM FREUd, LAPLANCHE E LACAN
}

Natália De Toni Guimarães dos Santos*

Isabel Fortes**

\section{Resumo}

Este artigo consiste numa pesquisa teórica sobre a noção de biológico na psicanálise a partir da revisão bibliográfica de Freud, Laplanche e Lacan. Nossa proposta é mapear algumas questóes relevantes sobre a inserção do biológico nas teorizaçóes freudianas, ao mesmo tempo que buscaremos delimitar a diferença desse autor em relação a Laplanche e a Lacan. Ao pensar a pulsão como um conceito na fronteira entre o psíquico e o somático, Freud estabelece a teoria do apoio, concebendo a sexualidade como um processo eminentemente intrapsíquico derivado da ordem do biológico. Laplanche segue Freud e a teoria do apoio, embora salientando a importância da intersubjetividade, do outro como agente instaurador do pulsional. Lacan, por sua vez, critica a teoria do apoio, apontando uma separaçáo radical entre o biológico e o sexual, acentuando a questáo da parcialidade das pulsóes.

Palavras-chave: psicanálise; biológico; pulsão; sexualidade.

\begin{abstract} AND LACAN

* Universidade Federal do Rio de Janeiro, Rio de Janeiro, RJ, Brasil.

** Universidade Federal do Rio de Janeiro, Rio de Janeiro, RJ, Brasil.
\end{abstract}

SOME CONSIDERATIONS ON THE FIELD OF THE BIOLOGICAL IN FREUD, LAPLANCHE

This article consists of a theoretical research on the biological notion in psychoanalysis starting from the bibliographical revision of Freud, Laplanche and Lacan. Our proposal is to map some relevant issues concerning the insertion of the biological notion in Freud's theorizations while seeking to outline its diffe- 
rence in relation to Laplanche and Lacan. Thinking the drive as a concept in the boundary between the psychological and the somatic, Freud establishes the supporting theory, conceiving the sexuality as an eminently intrapsychic process derived from the biological order. Laplanche follows Freud and the supporting theory although emphasizing the importance of intersubjectivity, placing the Other as a catalytic agent for the drive. Lacan on the other hand criticizes the supporting theory, pointing out a radical split between the biological and the sexual, hence defining satisfaction as pertaining to the order of partiality.

Keywords: psychoanalysis; biological; drive; sexuality.

\section{Resumen}

ALGUNAS CONSIDERACIONES SOBRE EL CAMPO DE LO BIOLÓGICO EN FREUD, LACAN Y LAPLANCHE

Este artículo es una investigación teórica sobre la noción de lo que es biológico en el psicoanálisis, a partir de la revisión bibliográfica de Freud, Lacan y Laplanche. Nuestra propuesta consiste en destacar algunas cuestiones relevantes acerca de la inserción de lo biológico en las teorías freudianas, mientras buscamos establecer la diferencia entre este autor, Laplanche y Lacan. Al pensar la pulsión como un concepto de frontera entre lo psíquico y lo somático, Freud establece la teoría del apoyo, al concebir la sexualidad como un proceso eminentemente intrapsíquico, derivado de la esfera de lo biológico. Laplanche sigue Freud y la teoría del apoyo, aunque señalando la importancia de la intersubjetividad, del otro como agente instaurador de lo pulsional. Lacan, a su vez, critica la teoría del apoyo, señalando una separación radical entre el campo de lo biológico y de lo sexual, al acentuar la cuestión de la parcialidad de las pulsiones.

Palabras clave: psicoanálisis; biológico; pulsión; sexualidad.

\section{Freud: a sexualidade em relação ao biológico}

A psicanálise inaugurou-se a partir da ruptura que Freud estabeleceu com a medicina da sua época, fortemente atrelada à biologia, à anatomia e à fisiologia. Já nas publicaçôes pré-psicanalíticas os sintomas histéricos foram descritos a partir de uma representação corporal atravessada pela linguagem. Com efeito, a originalidade freudiana insere-se no fato de conceber o psiquismo como sendo eminentemente um aparelho de linguagem. 
No entanto, o fato de a psicanálise se instituir numa descontinuidade radical com o campo da medicina não significa dizer que a biologia não tenha tido um lugar de destaque nas formulações de algumas concepções psicanalíticas. $\mathrm{O}$ presente artigo tem como objetivo destacar alguns pontos relevantes sobre a incidência da noçáo de biológico na constituição do psiquismo freudiano. Nossa proposta não é exatamente a de aprofundar a temática da biologia nas teorizaçóes freudianas, mas mapear algumas questóes que consideramos importantes para essa discussão e, ao mesmo tempo, demarcar certas diferenças da obra do psicanalista vienense com as contribuiçóes de Laplanche e de Lacan.

Assim, propomos inicialmente demonstrar como a noçáo de desamparo, a formulação das zonas erógenas e a própria conceituação da noção de pulsão encontram-se referidas ao campo do biológico.

No artigo "Projeto para uma psicologia científica", de 1895, Freud afirma que, ao nascer, o ser humano apresenta-se como um organismo dependente e vulnerável, que precisa descarregar suas excitações endógenas e ter suas necessidades satisfeitas. Devido às excitações internas oriundas das necessidades vitais, das quais não é possível esquivar-se, ocorre um acréscimo de tensão, impondo uma exigência de trabalho ao psíquico para manter a energia interna do organismo no nível mais baixo possível, segundo o princípio da constância, mas ela não pode ser dominada pelo aparelho psíquico da criança, ainda em vias de estruturar-se.

Esse estado originário situa a alteridade, portanto, no registro da dependência como condição para o surgimento do sujeito, que impóe a presença do outro para a sobrevivência do indivíduo. Eis aqui a imbricação entre a referência orgânica, marcada pela falta e pela precariedade, e a experiência psíquica que advém dessa condição de impotência no plano vital, concebida por Freud na noçáo de desamparo originário, o qual necessariamente remete ao outro como fundamento primordial para a constituição psíquica. A alteridade adquire aqui a condição de onipotência, influenciando de forma decisiva a estruturaçáo do psiquismo, destinado a se constituir inteiramente nessa relação com outrem.

A excitação proveniente do interior do corpo do bebê, justamente por sua incapacidade de pôr em ação os mecanismos que levam ao restabelecimento do equilíbrio, é sempre excessiva e atesta o estado de desamparo a que o ser humano está entregue. Nesse primeiro momento tal estado se refere à insuficiência do recém-nascido no que concerne à satisfação de suas necessidades vitais, sendo denominado, portanto, de "desamparo motor", que podemos correlacionar ao "desamparo biológico". Segundo Pereira (1999), o termo alemão motorische-psychische coloca em primeiro plano a dimensão da autoconservaçáo, na medida em que expressa a insuficiência performativa do bebê. Em um texto bem poste- 
rior, no qual a noção de desamparo é retomada pelo viés da angústia face à perda de objeto, Freud retoma esse momento inicial e demonstra como o desamparo é ao mesmo tempo psíquico e biológico, na medida em que cabe à mãe a satisfação de todas as necessidades do bebê. O desamparo psíquico é, nos termos do autor, "um símile natural de seu desamparo biológico" (Freud, 1926/1977, p. 162).

A questão central encontra-se aqui na compreensão de que o desamparo se vincula à prematuridade biológica, geradora da dependência ao outro. O desamparo é, portanto, o pressuposto para a entrada da alteridade, na medida em que o infans vai precisar do auxílio do outro para prover-lhe um objeto de satisfaçáo que reduza a tensão ocasionada pela necessidade (Freud, 1895/1977), na medida em que há, desde o início da vida, uma energia em ebulição no organismo que pressiona no sentido do escoamento, da descarga, da redução de tensão, conduzindo ao restabelecimento da homeostase. Assim, a partir da ajuda do outro, o aparelho psíquico terá como finalidade a infindável tarefa de dominar estímulos. A satisfação orgânica não garante de forma alguma a calmaria do aparelho psíquico, pois, embora a pressão das necessidades vitais tenha um ritmo natural e cesse temporariamente ao ser satisfeita, um processo de outra natureza aí tem início, reativando a pressão no aparelho psíquico que, dessa vez, age de forma constante, não concedendo qualquer trégua ao longo de toda a vida do sujeito.

Esses estímulos que se originam continuamente dentro do organismo e alcançam a mente, impondo uma exigência de trabalho ao psíquico, são denominados pulsóes (Freud, 1915/1977). Vindos do interior, os estímulos pulsionais atuam diretamente sobre a mente como representantes psíquicos das forças orgânicas, como medida da exigência de trabalho feita à mente em consequência de sua ligação com o corpo. Entre as principais características da pulsão, podemos apontar a fonte interna e a força constante, uma vez que ela jamais atua como um impacto apenas momentâneo. Como esses estímulos persistem apesar da açáo muscular descarregar parte deles para o exterior, eles se fazem sinais de um mundo interno, da existência de necessidades pulsionais sobre as quais nenhuma ação de fuga pode prevalecer. Com efeito, exercer pressão é a característica de toda pulsão, sendo essa a sua essência. Em momento algum ela se isenta de buscar o alvo da satisfação, que só pode ser obtida quando a estimulação na fonte da pulsão é eliminada.

A pulsão é definida como um conceito-limite entre o psiquismo e o somático, estando ligada ao representante como uma espécie de delegação pela qual o somático será representado no psiquismo. Assim, qualquer manifestação somática no psiquismo com necessidade de satisfação é o representante de uma pulsão. Cabe dizer que o circuito pulsional nesse primeiro momento da obra freudiana é 
circunscrito ao dualismo das pulsóes do ego ou de autoconservação em oposição às pulsões sexuais, inspirado na tradição mítica da distinção entre a Fome e o Amor.

A oposição entre pulsões sexuais e pulsões do ego presente no primeiro dualismo freudiano é relevante no que concerne à discussão sobre o biológico, na medida em que subjaz a essa oposição a ideia de que a pulsão sexual se apoia na pulsão do ego, compreensão central na formulação da teoria do apoio. Por outro lado, as pulsões do ego são também consideradas pulsões de autoconservação, indicando já nessa distinção o quanto a pulsão é limítrofe, o quanto só pode ser concebida na fronteira entre o orgânico e o psíquico. Em 1914, no artigo sobre o narcisismo, esse primeiro dualismo é visto sob a perspectiva de uma dupla função que acossa o ser humano:

O indivíduo leva realmente uma existência dúplice: uma para servir as suas próprias finalidades e a outra como um elo numa corrente [...]. O indivíduo considera a sexualidade como um dos seus próprios fins, ao passo que, de outro ponto de vista, ele é um apêndice de seu germoplasma, a cuja disposição póe suas energias em troca de uma retribuição de prazer [...]. A separação dos instintos [das pulsóes] sexuais dos instintos [das pulsóes] do ego refletiria essa função dúplice do indivíduo (Freud, 1914/1977, p. 94-95).

De todo modo, consideramos importante ressaltar que a pulsão de autoconservação ocupa um terreno de certa maneira nebuloso nas teorizaçóes freudianas, sendo dado um lugar de destaque à pulsão sexual na concepção freudiana do modelo das neuroses concebido no terreno do primeiro dualismo pulsional. Assim, em muitos momentos, o discurso freudiano deixa entrever que a pulsão sexual englobaria o campo da pulsão, ficando a pulsão de autoconservaçáo com uma circunscrição teórica que frequentemente não tem uma fronteira nítida em relação ao instinto. No entanto, consideramos relevante mostrar que no primeiro dualismo se funda a noção de apoio. Em relação a esta última, observa-se que, já no artigo de 1905, Freud parte das funçóes vitais para conceber as zonas erógenas. Se, por um lado, o modelo das neuroses se calca na pulsão sexual, por outro lado é inegável que a noção de funçóes vitais, ligadas à nutrição no ensaio de 1905 - que mais tarde se transformará na pulsão de autoconservação na elaboração do primeiro dualismo pulsional - oferece os subsídios para a formulação da teoria do apoio.

Cabe aqui ressaltarmos que o presente artigo trata da questão do biológico tomando como princípio norteador a primeira teoria das pulsóes em Freud. No 
quadro do segundo dualismo pulsional, a pulsão de autoconservação será englobada pelas pulsóes de vida, Eros envolvendo não somente a libido e os impulsos sexuais, mas também o que complexifica a questão do biológico no quadro teórico após a virada de 1920, a conservação da vida. Refletir sobre o biológico a partir do segundo dualismo pulsional não cabe no escopo do presente trabalho e será tema de reflexão em outro artigo, já em fase de germinação.

Com efeito, ao centrar na noção de apoio como uma das chaves principais de argumentação para pensar a presença do biológico não apenas na teoria freudiana, mas buscando também ver o seu alcance nas teorias laplancheana e lacaniana, o presente trabalho encontra-se circunscrito ao terreno do primeiro dualismo pulsional, na medida em que nesse campo a pulsão sexual encontra enorme vigor, sendo concebida a partir da sustentação na pulsão de autoconservação.

De acordo com a teoria do apoio, apresentada em "Três ensaios sobre a teoria da sexualidade" (1905/1977), ao mesmo tempo que, a serviço da manutenção da vida e da autoconservação, há a satisfação das necessidades, ocorre também uma satisfação sexual decorrente da erogeneização da zona ou do órgão em contato com o objeto, gerando um prazer para além da satisfação orgânica. O que inicialmente advém da satisfação das necessidades orgânicas se desdobrará e se transformará em satisfação sexual. Portanto, a satisfação sexual, no caso da zona labial, tem como alvo a incorporação do objeto, ocorrendo a ligação simultânea dessa parte do corpo com a alimentaçáo.

O termo apoio designa a relação que as pulsões sexuais originalmente mantêm com as funçôes vitais que lhes fornecem uma fonte orgânica, uma direção e um objeto específicos, sustentando-se, portanto, na pulsão de autoconservação. Esta, por sua vez, guarda forte ligação com o que é da ordem da vida, da necessidade, tendo como seu protótipo a fome. Assim, observa-se que na primeira mamada do bebê o objeto específico não é o seio, mas o leite que sacia a fome. A sucção tem a finalidade de obter o alimento que satisfaz o estado de necessidade orgânica, mas, paralelamente, dá-se também um processo de natureza sexual: a excitação dos lábios e da língua pelo seio, produzindo uma satisfação que não se reduz à saciedade alimentar, tratando-se antes de uma satisfação sexual que ganha autonomia sobre aquela.

Desse modo, a boca, órgão do sistema digestivo que tem a finalidade biológica de incorporar o alimento, é passível de ser erogeneizada e servir ao prazer sexual. Da mesma forma, todo órgão cuja excitação confere à pulsão um caráter sexual, isto é, libidinal, deve ser designado como zona erógena. A pele é a zona erógena por excelência e alguns órgãos são especialmente destinados à excitabilidade, mas qualquer parte do corpo pode assumir essa função. A energia pulsional 
tem sua fonte no processo somático excitatório em um órgão ou parte do corpo que tome para si as propriedades de uma zona erógena, dando origem às pulsóes parciais.

Reflexos da fragmentação do ser, esses componentes pulsionais são independentes entre si em seus esforços pela obtenção de prazer. Como emanam de uma grande variedade de fontes orgânicas, as pulsóes parciais são numerosas e só alcançam uma síntese quando a serviço da função reprodutora. Antes disso, a finalidade de cada uma delas é a consecução do "prazer de órgão" (Freud, 1915/1977). Nesse sentido, embora as pulsóes sejam inteiramente determinadas por sua origem numa fonte somática, na vida psíquica nós as conhecemos por suas finalidades, pela pressão que exercem no sentido de sua satisfação. Por isso, o conhecimento exato das fontes não concerne ao campo da psicologia e não é imprescindível para a investigação do psiquismo.

Nessa perspectiva, a noção de apoio seria a chave para a compreensão da pulsão, efeito marginal desse apoio-desvio que rompe com a ordem do natural. Ocorre aqui uma descontinuidade que designa a relação primitiva da sexualidade com a conservação da vida, mas que, ao mesmo tempo, assinala a distância entre a função conservadora e a pulsão sexual (Garcia-Roza, 1988). A variabilidade e a parcialidade do objeto da pulsão evidenciam esse hiato com relação ao instinto, pois este último implicaria em padróes fixos: objeto específico e objetivos restritos à conservação da espécie. $\mathrm{O}$ objeto da pulsão, ao contrário, é aquilo através do qual a pulsão é capaz de atingir sua finalidade, sendo o que há de mais variável na pulsão e, não estando a ela ligado originalmente, só lhe sendo destinado por ser peculiar e parcialmente propício a tornar possível a satisfação. "É provável que, de início, a pulsão sexual seja independente de seu objeto, e tampouco deve ela sua origem aos encantos deste" (Freud, 1905/1977, p. 139).

Assim, quando o objeto seio é abandonado, o objetivo e o objeto da pulsão sexual tornam-se independentes da alimentação e a necessidade de repetir a satisfação sexual desliga-se da necessidade de nutrição. O chuchar ou sugar com deleite, modelo das manifestaçôes sexuais infantis, consiste na "repetição rítmica de um contato de sucção com a boca (os lábios), do qual está excluído qualquer propósito de nutrição" (Freud, 1905/1977, p. 168). Essa atividade alia-se a uma absorção completa da atenção e leva ao adormecimento, ou mesmo a uma reação motora, descrita como equivalente a uma espécie de orgasmo. Constitui-se, dessa forma, a instauração do desejo e a entrada no sexual.

Um importante índice desse processo é o desenvolvimento da atividade de chupar o dedo, a qual dá início ao autoerotismo, conferindo à criança autonomia em relação ao objeto exterior. Logo, o objeto pode ser até uma parte do próprio 
corpo do indivíduo. Um recanto do lábio, o dedo ou qualquer outra parte do corpo pode ser tomada como objeto sobre o qual se exerce a sucção: "A inferioridade dessa segunda região a levará, mais tarde, a buscar em outra pessoa a parte correspondente, os lábios ('Pena eu não poder beijar a mim mesmo', dir-se-ia subjazer a isso)" (Freud, 1905/1977, p. 170).

Nesse sentido, ao se desvincularem das funções somáticas vitais, as pulsões sexuais impóem constantemente uma busca pela repetição da satisfação sexual primeira, aquela que traria novamente a experiência de completude ao ser por carregar a marca de um prazer absoluto, anterior a qualquer vivência de falta que, inevitavelmente, a criança experimenta ao buscar a reedição desse prazer. Este último segue sendo sempre almejado. Há primeiro a tentativa de alcançá-lo pela alucinação, mobilizada pelos processos primários que visam à descarga imediata; posteriormente, pela vigência do princípio de realidade, que instaura a capacidade de discernir entre o objeto fantasístico e o real. A primeira experiência de satisfação, portanto, funcionará doravante como uma espécie de bússola na busca do prazer, sendo ele irredutível à adaptação natural de um organismo (Freud, 1895/1977).

Ao longo da vida, o sujeito está implicado na busca do objeto perdido que lhe proporcionará a satisfação plena, sem jamais poder encontrá-lo. Mamar no seio familiarizou a criança com esse prazer que a pulsão sexual tentará sempre reencontrar, tornando-se paradigma para os relacionamentos amorosos. Podemos dizer, então, que, "embora sejam [as pulsóes] a suprema causa de toda a atividade, elas são de natureza conservadora; o estado, seja qual for, que um organismo atingiu dá origem a uma tendência a restabelecer esse estado assim que ele é abandonado" (Freud, 1938/1977, p. 161). As marcas do despontar da sexualidade, apesar de encobertas pela amnésia infantil, permanecem no psiquismo, atualizando-se durante toda a vida.

Freud, em alguns momentos, parece manifestar-se contraditoriamente quanto à participação do outro nesse processo originário. Por um lado, afirma que a sedução não é necessária para despertar a vida sexual da criança, já que ela também pode surgir espontaneamente, a partir de causas internas. Diz, inclusive, que a sedução pode confundir nosso olhar ao apresentar prematuramente à criança um objeto sexual do qual a pulsão sexual infantil náo tem necessidade alguma ${ }^{1}$. Por outro lado, também hesita em relação a isso: "Contudo, devemos admitir que também a vida sexual infantil, apesar da dominação preponderante das zonas erógenas, exibe comportamentos que desde o início envolvem outras pessoas como objetos sexuais" (Freud, 1905/1977, p. 179). Como exemplo, aponta a pulsão escópica que, embora fundamental para a formação do ego, mantém certa independência das zonas erógenas, ficando referida à presença do outro. 
Deduzimos, entáo, que a relação do psiquismo e da sexualidade com o organismo é de suma importância no campo psicanalítico, na medida em que estamos tratando do alicerce do sujeito, do originário, que não poderia deixar de trazer imensa complexidade. Prova disso é o fato de Freud ter inserido modificaçóes nos "Três ensaios sobre a teoria da sexualidade" ao longo de toda a evolução de sua obra. Citamos aqui duas passagens do prefácio da terceira (1914) e da quarta edição (1920), respectivamente, que deixam entrever que a investigação sobre o biológico foi reiteradamente retomada no percurso teórico freudiano: "A rigor, meu objetivo foi sondar o quanto se pode apurar sobre a biologia da vida sexual humana com os meios acessíveis à investigaçáo psicológica” (1905/1977, p. 124). E posteriormente: "Mas a parte da doutrina que faz fronteira com a biologia, cujas bases são fornecidas neste pequeno escrito, continua a enfrentar um dissenso indiminuto" (1905/1977, p. 125).

\section{Laplanche: a sedução originária e a intersubjetividade}

A prematuração no domínio da sobrevivência e no domínio da sexualidade é consensualmente entendida na psicanálise como uma condição fundamental do ser humano. Assim como Freud, Laplanche (1987) afirma que, ao nascer, o lactente já é munido de montagens fisiológicas e psicofisiológicas, mas elas são imperfeitas e só se estabilizam progressivamente, o que lhe traz o risco, por exemplo, de morte em virtude de um forte calor ou por desidrataçáo. Por outro lado, essas montagens conferem esquemas perceptivo-motores que lhe permitem uma abertura para o mundo. Contudo, a criança permanece profundamente desamparada no confronto com tarefas de nível alto relativamente ao seu grau de maturação psicofisiológica, necessitando de ajuda alheia.

Os cuidados corporais dispensados ao filho pela mãe ou substituto provocam a erogeneidade do corpo, proporcionando sensaçóes prazerosas, veiculando fantasias do desejo inconsciente do adulto. Percebemos, aqui, a identidade entre essa perspectiva de Laplanche e o ponto de vista de Freud a esse respeito.

Laplanche (1987) chama de situação originária esse confronto do recém-nascido com o mundo adulto. A relação adulto-criança, radicada nos planos biológico e pulsional, tem, segundo o autor, um caráter universal, inegável, fora das contingências, uma vez que é efetiva, essencial e criadora. Essa situação é originária do psiquismo porque ocorre a sedução da criança pelo adulto: em posição assimétrica, passiva diante do adulto e de seu inconsciente, ela entra em confronto com os enigmas da sexualidade que lhe impóem trabalho psíquico e 
instauram a pulsão (Laplanche, 1987). O mundo adulto não é algo objetivo que a criança tem que apreender, se caracteriza por mensagens que lhe são dirigidas e que a interrogam, impelindo-a a tentar compreendê-las, dando-lhes um sentido e uma resposta.

Quando a tensão interna aumenta, a "única maneira de pedir ajuda não é justamente um pedido, uma mensagem, mas um simples índice objetivo" (Laplanche, 1987, p. 104), como um grito, por exemplo, a que a mãe ou seu substituto vai dar sentido e, dessa forma, antecipar seu desejo. Essa linguagem do adulto, na qual a criança preexiste, é traumatizante porque veicula um sentido em si ignorado pela criança. Ela manifesta a presença do inconsciente parental, mas ao mesmo tempo sofre o retorno do recalcado, que incide sobre o corpo da criança, imprimindo-lhe as marcas desse encontro primordial com a alteridade, que é traumático na medida em que há uma exterioridade radical do lugar do outro em relação ao sujeito. É o outro, enquanto mediador, que, ao relacionar-se com a criança proporcionando o objeto necessário à satisfação, a leva a confrontar-se com o enigma de seu desejo e de sua sexualidade inconsciente. As mensagens enigmáticas provenientes do cuidado do outro instauram o trauma do aparelho psíquico, essencialmente um aparelho de captura das excitaçóes, que impele a dar sentido às intensidades.

Trata-se aqui de unidades perceptivas e de significantes não ligados que acossam a criança, que, em razão de sua passividade e de seu despreparo, não é ainda capaz de representar tais intensidades. Em um primeiro nível de simbolização, a rede de significantes que vem do outro é lançada sobre o universo subjetivo, mas nenhum significado particular pode ser capturado. Os elementos das mensagens enigmáticas do outro permanecem como enclaves não articulados no psiquismo e se constituem como os objetos-fonte da pulsão, pressionando no sentido da ligação e da descarga e, desse modo, dando origem ao inconsciente individual de cada um de nós. Como a mensagem permanece em estado selvagem e os significantes, enigmáticos, o inconsciente se estrutura como uma linguagem antes da própria linguagem.

O enigma, que é a sedução em si mesma, consiste em um trauma estruturante do sujeito a partir dessa falta, desse irrepresentável ao qual é confrontado. Para Laplanche, é necessária a participaçáo do outro, do adulto cuidador, para que o pulsional se instaure. Aqui, tudo é ao mesmo tempo exógeno e endógeno, pois é preciso que haja a intersubjetividade para que o intrapsíquico se produza, para que uma interioridade se constitua. É, então, a relação com o outro que introduz o pulsional. Essa é uma etapa puramente mítica, pré-histórica, em que os movimentos reais de estruturaçáo do sujeito psíquico se dão, mesmo que não 
possam ser capturados, mas apenas cercados, inferidos, antes que o próprio sujeito advenha como tal.

Destacamos aqui uma distância de Laplanche com relação a Freud, que, embora hesitante, como mostramos, concede relevância ao intrapsíquico no surgimento da pulsão sexual. Nas palavras de Freud: "É evidente que a sedução não é necessária para despertar a vida sexual da criança, podendo esse despertar surgir também, espontaneamente, de causas internas" (Freud, 1905/1977, p. 178). Parece que, nesse âmbito, Freud não confere tanta importância quanto Laplanche à dimensão intersubjetiva, relacional, dando prioridade à fonte interna de estimulação, mesmo que não à fonte no sentido estritamente fisiológico, salientando a reverberação sexual de tudo o que se passa no organismo. Com isso, todo processo vital pode despertar a sexualidade.

A partir do apoio, Freud explica a instauração do pulsional como inerente aos estímulos endógenos advindos das necessidades vitais. Laplanche, mesmo tendo dado visibilidade e destaque no campo psicanalítico pós-freudiano a essa noção (Garcia-Roza, 1995), tem uma concepção diferente sobre a mesma, inserindo nuances na questão da relação da sexualidade com o biológico. $\mathrm{O}$ autor francês primeiramente destaca a relação entre pulsão e instinto, evidenciando mais as semelhanças do que as diferenças entre ambos, pois, ainda que os reconheça em sua especificidade, a análise da pulsão em seus elementos, como realizada por Freud nos textos de 1905 e, principalmente, de 1915, seria válida também para o instinto. A importância dada aqui à noção de instinto para se pensar a pulsão é de tal monta que Laplanche chega a dizer que "Tratar da pulsão em geral é 'biologizá-la', é apresentar uma análise que seria válida também para os comportamentos ditos instintuais" (Laplanche, 1985, p. 21). Ao contrário da pulsão, no entanto, o instinto é definido como comportamento performado, cujo esquema é hereditariamente fixado e tende a se repetir.

Laplanche ressalta que a derivação da pulsão a partir do instinto não é só conceitual, mas também real, pois a sexualidade infantil se desenvolve tendo como suporte a função corporal essencial à ordem da vida (sucção), ou seja, o instinto. São descritos, então, dois tempos da oralidade, o que não significa considerar a ordem vital como infraestrutura, como um a priori, pois o caráter profundamente imaturo das funçôes vitais do ser humano é justamente o que convoca de imediato a introdução da sexualidade. "Ao contrário do que se pensa, não é através da florescência que a ordem vital resulta na sexualidade, mas é pela sua insuficiência que ela solicita a intrusão do universo adulto" (Laplanche, 1985, p. 54).

Assim, à incorporaçáo facultada pela pulsáo oral associa-se a fantasia, que não se reduz à simples ingestão de alimento. Esse segundo momento, o chupar, 
é, para Freud, o que inaugura a sexualidade em sua forma autoerótica, um tempo de perda do objeto parcial (o seio), já que, originalmente, antes de ocorrer o desvio da ordem do natural, esse foi o objeto da pulsão, localizado fora do corpo da criança. $\mathrm{O}$ autoerotismo, portanto, não é primário, e sim a necessidade do objeto externo.

Por isso, a hipótese levantada por Freud em 1905, a qual supóe a independência da pulsão, desde o início, em relação a um objeto, soa, para Laplanche, como uma "espécie de estado de idealismo biológico, ainda mais impensável que o solipsismo filosófico", uma "certa aberração do próprio pensamento freudiano relativo ao 'objeto' e à ausência primitiva de objeto" (Laplanche, 1985, p. 26). Afirmar que o autoerotismo, momento intimamente ligado ao apoio, caracteriza-se pela ausência do objeto e pela atividade sexual não dirigida a uma pessoa (sendo seu objetivo determinado pela atividade de uma zona erógena) implica em admitir que, posteriormente, o objeto apareceria ex nibilo, a partir de um estágio inicial tido como "anobjetal", o que Laplanche considera muito pouco provável.

Por um lado, há objeto desde o início; por outro, a sexualidade não tem objeto real, pois o leite é objeto da função vital na qual a pulsão sexual se apoia. Na leitura de Laplanche, é justamente esse objeto real - o leite - o objeto perdido, a partir do qual surge o prazer sexual. Nesse sentido, a fonte da pulsão seria o "instinto todo" (Laplanche, 1985, p. 29). Já o objeto ligado ao retorno do autoerótico, o seio, é transformado em fantasmático, sendo ele próprio o objeto da pulsão sexual. Assim, o objeto sexual não se superpóe ao objeto da função, na medida em que se encontra deslocado em relação a este, numa relação de contiguidade que o faz deslizar insensivelmente de um para o outro, do leite ao seio, como seu símbolo.

Dessa forma, o objeto a ser reencontrado não é o objeto perdido, mas o seu substituto por deslocamento. A impossibilidade de reencontrar o objeto funda-se, para Laplanche, não num suposto objeto sexual inaugural da primeira experiência de satisfação, consagrado como fonte do prazer absoluto, guia de todas as escolhas de objeto posteriores; mas no fato de o objeto perdido não ser o mesmo que aquele que se deseja reencontrar, uma vez que pertence ao campo instintual dos objetos reais que, pela relação de contiguidade com o objeto fantasmático da pulsão, reveste-se de elevado valor simbólico. $\mathrm{O}$ reencontro sempre se constitui como reencontro de outra coisa. Eis a força do engodo essencial que estrutura a procura sexual.

Esse descompasso estrutural reflete, no sujeito, a relação entre a aculturação e o biológico. A sexualidade orgânica, genital, que já é parcialmente "desnaturada”, vem tarde demais, após a puberdade, não oferecendo à criança compo- 
nentes afetivos e representativos suficientes para "integrar" a cena sexual primária e compreendê-la. Por isso, ao mesmo tempo, a sexualidade vem cedo demais, do exterior, como relaçáo inter-humana, traduzida pelo mundo adulto. Trata-se de uma noção mais ampla de sexualidade, na medida em que passamos do sexual como instinto vital ao sexual como perversão universal do instinto, como desvio originário que destrói qualquer noção de norma biológica. A ideia de "prazer de órgão" designa justamente essa perversão do instinto, o prazer localizado, autoerótico, que se opóe à ideia de um "prazer de função", com tudo o que esse termo implica em abertura para o objeto.

Nesse sentido, a pulsão parece conter nela própria o seu objeto, uma vez que ele é indiferente, absolutamente contingencial, ao passo que o objeto do instinto é preciso, específico. Ainda assim ela depende de uma intervenção externa para despontar, pois Laplanche entende a sedução como um fato universal, na medida em que a prematuraçáo biológica do ser humano impóe a presença de um outro mais experiente que possa prover o objeto de satisfação das necessidades vitais.

Entendemos que, para Freud, existe uma predisposição filogenética para a sexualidade, oriunda de vivências prévias da espécie, as quais a ontogênese do indivíduo reproduz, desde que não seja modificada por fatores acidentais da experiência recente. A sexualidade enquanto potência já nasceria com o ser humano, precisando somente ser ativada, o que se daria de forma quase automática, colada à satisfação orgânica, conforme a teoria do apoio. Já para Laplanche, é somente a partir do outro primordial que o psiquismo da criança é instigado a entrar no registro sexual. Entrada que depende do estabelecimento de uma relação, ainda que assimétrica e não vivenciada pela criança enquanto tal. "A sexualidade surge, no pequeno ser humano, por desvio e retorno autoerótico dos processos vitais. Por outro lado, a sexualidade - tomando-se sempre esse termo na sua acepção 'generalizada' - aparece como que implantada na criança a partir do universo parental, de suas estruturas, de suas significaçóes e de suas fantasias" (Laplanche, 1985, p. 54).

\section{Lacan: deiscência e urgência da vida}

Lacan considera também fundamental a precariedade e imaturidade constitucional do ser humano para a inevitável e necessária dependência em relação à alteridade, sendo esta a condição imprescindível para a inserçáo do sujeito no campo do humano, da sexualidade e da cultura. A prematuração biológica do 
ser humano ao nascer é evocada nos primeiros escritos desse autor sob o termo "deiscência". Em "O estádio do espelho como formador da função do eu" (1949/1998), Lacan apresenta a constituição imaginária do eu a partir de um estado primário de insuficiência psicomotora da criança, tendo como preço a alienação ao Outro. A prematuração do nascimento e a ineficiência orgânica são os pressupostos teóricos necessários para a tese do estádio do espelho.

Tal tese concebe que a forma total do corpo da criança que se vê refletida no espelho e nomeada pelo Outro é constituidora do eu. A assunção jubilatória da imagem especular de um ser ainda mergulhado na impotência motora e na dependência manifesta a matriz simbólica em que o eu se precipita em uma forma primordial, antes de se objetivar na dialética da identificação com o Outro e antes que a linguagem lhe restitua sua função de sujeito. Em uma miragem, o sujeito antecipa a maturação de sua potência a partir de uma Gestalt capaz de efeitos formadores sobre o organismo, possibilitando a simbolização da permanência mental do eu na estátua em que o homem se projeta. Podemos dizer que o fenômeno do estádio do espelho repousa sobre o corpo orgânico fragmentado, com o intuito de unificá-lo.

Na projeção especular, no entanto, há certa estranheza, por conta do desajuste entre a imagem unificada e as sensaçóes de despedaçamento, por falta de coordenação motora e pelo inacabamento anatômico, que evidenciam a prematuração específica do nascimento no homem. A discordância primordial entre a imagem e o real do corpo traduz-se como o que Lacan denomina deiscência - alteração na relação do homem com a natureza por conta da insuficiência orgânica de sua realidade natural.

$\mathrm{O}$ eu se constitui a partir de uma alienação ao outro, que se relaciona ao investimento lidibinal próprio desse momento, designado como narcisismo primário, na medida em que investir em si mesmo só é possível a partir do investimento prévio dos pais, que revivem através do filho seu narcisismo perdido. Assim, ocorre a instauração, no psiquismo da criança, desse objeto imaginário que virá a constituir seu eu pelo processo de identificação. $\mathrm{O}$ eu configura-se, portanto, como um núcleo de servidão imaginária que, nas origens, liga a criança à mãe e se conserva como uma estrutura intrassubjetiva no narcisismo.

Essa captação identificatória pela imago, forma definível no complexo espaço-temporal imaginário, realiza a identificação resolutiva de uma fase psíquica que representa a metamorfose das relaçóes do indivíduo com seu semelhante. $\mathrm{O}$ sentido existencial desse fenômeno, como vimos, relaciona-se com a prematuração do nascimento do homem, com a incompletude e o "atraso" do desenvolvimento durante os primeiros seis meses de vida, os quais se manifestam pela des- 
coordenação motora do lactante. "É em função desse atraso do desenvolvimento que a maturação precoce da percepçáo visual adquire seu valor de antecipação funcional" (Lacan, 1949/1998, p. 187), a qual irá constituir no homem o nó imaginário e absolutamente essencial que a psicanálise chama de narcisismo.

Assim sendo, pode-se vislumbrar que o homem é muito mais que seu corpo, ao mesmo tempo que nada mais pode saber sobre seu ser. Esse eu, narcísico, que se origina a partir do investimento do outro e se configura como objeto de amor para o próprio sujeito, não deve ser confundido com o ser do sujeito, pois o eu imaginário que surge no narcisismo permite que o sujeito se reconheça enquanto indivíduo, mas ao preço de apartar-se de sua verdade, daquilo que o causou e que se encontra no campo da alteridade.

Com efeito, a maturaçáo do aparelho psíquico do infans depende da intermediação cultural que se dá pela inserção no simbólico, no campo do Outro, possibilitada por seus cuidadores desde antes de seu nascimento. Com a noção de estádio do espelho, que ilustra um caso particular da função da imago - estabelecer uma relação do organismo com sua realidade -, Lacan descreve um tempo de subjetivação em que a criança começa a identificar a si mesma como objeto total e assim se integra, constituindo um eu. Esse processo já acontece de forma parcial desde o primeiro contato com seus outros, mesmo antes do nascimento, quando já se sabe que há, no feto, por exemplo, percepção acústica. Na leitura lacaniana, as imagens dos corpos no espelho, na medida em que são empregadas como significantes e entram em relação, representam algo que adquire valor de orientação ao penetrar na criança. Ocorre aqui a identificação, a forma mais originária de laço afetivo com um objeto.

A ênfase na linguagem e na identificação faz com que em Lacan a ordem da vida assuma uma perspectiva bem diferente da de Freud, que associa o surgimento da pulsão sexual a uma fonte orgânica, análoga à da necessidade vital. Lacan (1964/1985) entende a referência orgânica relacionada ao estado de urgência da vida, o qual impóe necessariamente a parcialidade às pulsóes, uma vez que o campo pulsional não constitui uma totalidade biológica, chamando atenção para uma não adaptação radical do ser humano. "É em razão da realidade do sistema homeostático que a sexualidade só entra em jogo em forma de pulsóes parciais" (Lacan, 1964/1985, p. 167). Embora Freud afirme que as pulsóes sexuais são numerosas e atuam em princípio independentemente umas das outras, alcançando uma síntese mais ou menos completa em uma fase posterior, para Lacan, pela própria essência do pulsional, essa síntese é impossível, sendo a pulsão sempre parcial.

O fato de a sexualidade só se realizar por operação das pulsóes parciais nos conduz a uma problematização do alvo da pulsão. Em Freud, a satisfação 
pulsional pode ser alcançada desde que tenha sido vivenciada antes, vindo daí o impulso para a sua repetição. No entanto, há em Freud certa correlação ainda com as funçóes vitais na formação das zonas erógenas. Já em Lacan, a pulsão encontra-se completamente apartada de qualquer função biológica, podendo atingir a satisfaçáo única e exclusivamente desde a sua parcialidade: "Se a pulsão pode ser satisfeita sem ter atingido aquilo que, em relação a uma totalização biológica da função, seria a satisfação ao seu fim de reprodução, é que ela é pulsão parcial, e que seu alvo não é outra coisa senão esse retorno em circuito" (Lacan, 1964/1985, p. 170). O alvo, aqui, encontra-se bem distante da saciação da necessidade, na medida em que Lacan dá ênfase a um movimento em circuito que é feito pelas bordas do corpo e não pela conexão com esta ou aquela zona específica.

Com efeito, no Seminário, livro 11, a pulsão é circunscrita à dialética do arco e flecha, na qual o que é fundamental no nível de cada pulsão é o circuito de vaivém que ela percorre pelas bordas e pela superfície do corpo, não importando aqui a função vital da parte do corpo em questão. Desse modo, dá-se destaque ao caráter circular do percurso da pulsão, aludindo à imagem de uma flecha (Drang, força) que atravessa a superfície, a borda (Quelle, fonte, zona erógena) - aquilo que está na fronteira entre o interno e o externo e se presta à função sexual -, fazendo uma curva que parte e retorna à borda, fechando-se sobre si mesma (Lacan, 1964/1985).

Se na teoria freudiana podemos afirmar que em certa medida a satisfação pulsional derivaria da ligaçáo simultânea da zona labial com a alimentação, sendo difícil discernir, em um recém-nascido, a satisfação da necessidade do que poderia ser apenas o prazer de sugar, na teoria lacaniana a importância do biológico não se dá por meio de qualquer objeto relativo às funçôes vitais, pois o despertar da pulsão encontra-se em lugar distinto do da satisfação instintual. Daí a crítica de Lacan à ideia de apoio, uma vez que, para ele, a sexualidade está desde sempre apartada do biológico por sua própria constituição.

O Not des Lebens é, assim, o fato da premência de satisfação, da necessidade vital em geral e não a simultaneidade da pulsão a um objeto, pois nenhum objeto da necessidade pode satisfazer a pulsão. Não é pelo alimento que a boca se satisfaz, mas pelo prazer da boca, que não poderia ser reduzido à mera função de adaptação. Distinguir-se-ia, portanto, no começo da dialética da pulsão, a ordem da necessidade do campo da exigência pulsional (Lacan, 1964/1985). Portanto, não é necessariamente no ato mesmo de satisfação de uma necessidade que se inaugura o desejo por apoio no fisiológico. Isso pode se dar independentemente do campo das necessidades.

Nesse sentido, podemos afirmar que a pulsão sexual surge a partir da relação com o Outro. "Algo do desejo da mãe sobre a criança seria traduzido pelos 
traços de seu rosto" (Laznik, 2000, p. 81), bem como por seu olhar e por sua voz, identificados pelo bebê antes mesmo da primeira mamada, ou seja, antes mesmo de qualquer experiência de satisfação. Para a autora, a leitura lacaniana indica que a subjetivação não se dá pela inscrição psíquica da experiência de satisfação da necessidade pela via oral, despertando um prazer sexual que posteriormente a criança buscaria reeditar, mas pela incorporação dos traços dos pais, daqueles que investem libidinalmente nessa relação primordial.

Desse modo, destacamos uma divergência entre o pensamento de Lacan e o de Laplanche no que concerne ao tema da função biológica: para o primeiro, o inconsciente da criança se estrutura por uma interiorização do discurso do Outro ou do desejo da mãe; para o segundo, há sempre espaço para que algo do próprio sujeito se produza. A estruturação psíquica seria, assim, o resultado de um metabolismo que implica decomposição e recomposição (Bleichmar, 1993). A criança seria seduzida por um adulto, mas não se alienaria completamente no campo do Outro, já que a pulsão introduzida a partir daí é por definição ativa e pode engendrar a formação do eu.

\section{Consideraçóes finais}

Não se pode negar, em psicanálise, a relevância da determinação biológica na instauração da sexualidade. Ponto comum entre os autores estudados, inclusive, é o fato de que, justamente por conta da insuficiência no plano biológico e da prematuração da espécie humana, o humano rompe com a ordem do natural e se insere pela alteridade no campo da cultura e da sexualidade. Dentre os autores estudados, observamos que Laplanche, ao destacar a centralidade da noção de apoio, é o que mais afirma a importância do biológico e a proximidade entre a pulsão e o instinto. Em Freud, o biológico se apresenta como a fonte que faz com que a ordem da necessidade exerça um impulso que impele o psiquismo a trabalhar. Lacan, com a ênfase na linguagem e nas identificações no que diz respeito à constituição do campo do sexual, pode ser considerado aquele que acentua de forma mais radical a descontinuidade entre o biológico e o sexual.

Portanto, podemos observar o quanto a relação entre o biológico e o despontar da sexualidade é bastante complexa e repleta de nuances. Percorrer esses diferentes campos teóricos nos permite entender como cada autor organiza seu pensamento e a que aspectos cada um confere maior relevância. Freud inventa a psicanálise como um ávido pesquisador que a cada achado reorganiza seu arcabouço teórico de forma a fazê-lo ressoar com a prática clínica. A partir dele, a 
psicanálise é pensada e repensada, colocada à prova constantemente, deixando-se sempre aberta à possibilidade de novas leituras.

\section{Referências}

Bleichmar, S. (1993). O conceito de neurose na infância a partir do recalcamento originário. In S. Bleichmar, Nas origens do sujeito psíquico: do mito à história (pp. 20-40). Porto Alegre: Artes Médicas.

Freud, S. (1977). Projeto para uma psicologia científica. In S. Freud, Edição standard brasileira das obras psicológicas completas de Sigmund Freud (v. I, pp. 381-456). Rio de Janeiro: Imago. (Publicado originalmente em 1895)

Freud, S. (1977). Três ensaios sobre a teoria da sexualidade. In S. Freud, Edição standard brasileira das obras psicológicas completas de Sigmund Freud (v. VII, pp. 123-252). Rio de Janeiro: Imago. (Publicado originalmente em 1905)

Freud, S. (1977). Sobre o narcisismo: uma introdução. In S. Freud, Edição standard brasileira das obras psicológicas completas de Sigmund Freud (v. XIV, pp. 85-119). Rio de Janeiro: Imago. (Publicado originalmente em 1914)

Freud, S. (1977). A pulsão e os destinos da pulsão. In S. Freud, Edição standard brasileira das obras psicológicas completas de Sigmund Freud (v. 14, pp. 129-162). Rio de Janeiro: Imago. (Publicado originalmente em 1915)

Freud, S. (1977). Inibiçóes, sintomas e ansiedade. In S. Freud, Edição standard brasileira das obras psicológicas completas de Sigmund Freud (v. 20, pp. 95-204.). Rio de Janeiro: Imago. (Publicado originalmente em 1926)

Freud, S. (1977). Esboço de Psicanálise. In S. Freud, Edição standard brasileira das obras psicológicas completas de Sigmund Freud (v. 14, pp. 163-237). Rio de Janeiro: Imago. (Publicado originalmente em 1938)

Lacan, J. (1998). O estádio do espelho como formador da função do eu. In J. Lacan, Escritos. Rio de Janeiro: Jorge Zahar. (Publicado originalmente em 1949)

Lacan, J. (1985). O seminário, livro 11: os quatro conceitos fundamentais da psicanálise. Rio de Janeiro: Jorge Zahar. (Publicado originalmente em 1964)

Garcia-Roza, L. A. (1988). Freud e o inconsciente. Rio de Janeiro: Jorge Zahar.

Garcia-Roza, L. A. (1995). Introdução à metapsicologia freudiana - 3. Rio de Janeiro: Jorge Zahar. Laplanche, J. (1985). Vida e morte em psicanálise. Porto Alegre: Artes Médicas.

Laplanche, J. (1987). Fundamentos: para a teoria da sedução generalizada. In J. Laplanche, Novos fundamentos para a psicanálise (pp. 95-156). Lisboa: Ediçōes 70.

Laznik, M-C. (2000). A voz como primeiro objeto da pulsáo oral. Estilos da clínica, 5(8), 80-93.

Pereira, M. E. C. (1999). Pânico e desamparo. São Paulo: Escuta. 


\section{Nota}

${ }^{1} \mathrm{Na}$ Carta 69 (1897), Freud já reconhecia que as moções sexuais atuavam normalmente nas crianças de mais tenra idade, sem nenhuma necessidade de estimulação externa (Freud, 1905/1977).

Recebido em 08 de novembro de 2011 Aceito para publicação em 29 de agosto de 2012 